\title{
ENVIRONMENTAL ASSESSMENT AND INFESTATION LEVEL OF THE DENGUE VECTORS AT RESIDENTIAL AREA IN PUNCAK ALAM, SELANGOR
}

\author{
FATIN AZURA ${ }^{1}$, NAZRI CHE DOM* ${ }^{* 1,2}$ AND SITI NAZRINA CAMALXAMAN ${ }^{1,2}$ \\ ${ }^{1}$ Centre of Environmental Health \& Safety, ${ }^{2}$ Integrated Mosquito Research Group (IMeRGe), Faculty of Health Sciences, \\ Universiti Teknologi MARA, 42300 Puncak Alam, Selangor, Malaysia.
}

*Corresponding author: nazricd@uitm.edu.my

Submitted final draft: 21 May 2020 Accepted: 3 June 2020

http://doi.org/10.46754/jssm.2021.01.011

\begin{abstract}
The control of mosquitoes in residential areas calls for in-depth knowledge of the breeding habits of the mosquitoes, especially Aedes aegypti and Aedes albopictus. Therefore, this study aims to assess the environmental condition and infestation level of Aedes vectors at selected residential areas in Puncak Alam, Selangor. The aims of this study are to understand the environmental profile of residential areas towards infestation level of dengue vectors. A pilot study was conducted in Puncak Alam in order to understand the infestation profile of dengue vectors in residential areas by assessing the environmental condition index (ECI) in front and yard area of residential area. In this study, a minimum of a hundred houses in each residential area was observed for the environmental condition of front and yard of the premises. Concurrently, a total of thirty ovitraps were placed randomly at outdoor premises in order to measure the infestation level of the Aedes mosquitoes. A total of 318 households were inspected in both front area $\left(\mathrm{F}_{\mathrm{A}}\right)$ and yard area $\left(\mathrm{Y}_{\mathrm{A}}\right)$ where in general, the environmental condition in front of houses is better than the yard area. The same pattern was also observed in which the infestation level of Aedes mosquito population in $\mathrm{F}_{\mathrm{A}}$ and $\mathrm{Y}_{\mathrm{A}}$ ranged from 15.40 - 35.25 and 11.88 - 47.91, respectively. In conclusion, environmental conditions play a main role in the distribution of dengue vector.
\end{abstract}

Keywords: Residential area, environmental condition, infestation level, Aedes.

\section{Introduction}

Urbanisation is a factor that can increase the number of preferred habitats for Aedes mosquito thus increasing the density and survival of Aedes mosquito especially in a residential area (Saleeza et al., 2011). Another factor that contributes in dengue transmission and distribution is environmental parameters. This parameter can cause changes in dengue transmission that is related to the host, such as the demographic pattern. Furthermore, the land use such as housing type, soil moisture and greenness can contribute to the epidemic of dengue transmission (Aziz et al., 2011).

Community areas, particularly residential areas, are located in close proximity to major mosquito habitats. Previous entomological studies showed that dengue vectors have been captured in vegetated areas (Hayden et al., 2010; Vezzani et al., 2005), rubber plantations (Paily et al., 2013; Sumodan, 2003), marshy swamps
(Sarfraz et al., 2012) and brackish waters (Idris et al., 2013; Ramasamy et al., 2011). The presence of vegetation condition between community area and mosquito breeding site provides a disposal route for biting insect to community areas. According to Kesetyaningsih et al., (2016) the mosquito survival was affected by humidity that is maintained by the presence of vegetation. Next, human ecology is responsible for the creation of a mosquito genic environment. Generally, residential area is a potential source for the existence of breeding sites due to environment condition, either indoor or outdoor area.

Vector surveillance can be used to determine changes in the distribution and vector density and to obtain relative control measurement of the vector population. It also can serve to identify high-density infestation study area and selection of sampling method depending on the vector surveillance objective. Thus, several 
indices have been described as vector population monitor for dengue transmission. There are three approaches of dengue measures commonly used in Aedes surveillance in residential areas namely: (i) premise condition index (Roberto et al., 2013; Parasuraman et al., 2012a) (ii) ovitrap surveillance (Rozilawati et al., 2007 and Ligia et al., 2013) and (iii) integrating both approaches (Roberto et al., 2013 and Leticia et al., 2005). Premise condition index (PCI) value score indicates a simple index incorporating predictor of the mosquito breeding (house condition, yard tidiness and degree of shade) that does not require indoor inspection of the premises (TunLin et al., 1995). However, vulnerability of the PCI includes inability of the inspector to observe many rear yards' condition and the risk of seeing inconsistent PCI scoring between different inspectors (Parasuraman \& Radhakrishnan 2012b). Review conducted from Ligia et al., (2013) showed that mosquito behaviour is the main factor in the disease epidemiology transmitted by mosquitoes. Therefore, the ovitrap acts as an effective tool for providing spatial and temporal data in dengue control measures. In general, most of the surveillance studies, either the epidemiological evidence or quantitative methods were used for assessing the dengue transmission.

Ovitrap surveillance was used as a sampling technique to detect and measure the density of mosquito population by measuring the positive ovitrap index (POI) (Ligia et al., 2013; Wan Norafikah et al., 2009; Rozilawati et al., 2007). POI is a percentage of Aedes positive ovitrap divided by number of ovitraps collected from the study (Wan Norafikah et al., 2009). Prevention and control measures of the dengue disease are dependent on vector surveillance and control measures by integrating both approaches of ovitrap surveillance and the environmental condition index (ECI) as an indicator of mosquito infestation that could be used to relate between ECI and infestation to determine the density of mosquito population (Roberto et al., 2013). The ovitrap has been used as a proxy to measure a number of adult mosquitoes present from the total number of eggs laid in their habitat. Therefore, this study was aimed to assess the environmental condition and infestation level of Aedes vectors at selected residential areas in Puncak Alam, Selangor.

\section{Materials and Methods}

\section{Study Site and Study Population}

Puncak Alam is the main township development in the Kuala Selangor District, State of Selangor, Malaysia and has been selected as the case study area. Kuala Selangor District is one of the less urbanised districts in Selangor. It is located approximately 20 kilometres in the northwest direction from Shah Alam, the state capital of Selangor. Puncak Alam development started in the late 90's under the management of Bukit Cherakah Development Sdn Bhd with approximately $57 \mathrm{~km}^{2}$ in size. Currently, most of the developments in Puncak Alam are housing area with a small percentage of commercial and industrial units. As a sub-urban area, Puncak Alam is surrounded by rural lands within the boundary of Kuala Selangor district. Puncak Alam was selected due to its population distribution with a variety of new residential areas and has a significant public health implication in relation to control and prevention of dengue outbreak.

\section{Study Design}

A minimum of 318 houses in selected residential areas in Puncak Alam was inspected in each zone (A, B and C). Within the selected residential area 30 houses chosen randomly/ zones were used to observe the condition of the environment and to measure the infestation of Aedes vectors, using ovitrap. The front and back yards of the premises were used to evaluate the environmental condition of the residential areas using the criteria that contribute to the existence of mosquito activities which include house maintenance, solid waste management, degree of shade and drainage facilities. Then each premise was scored from lower to the highest according to the method developed by Tun-Lin et al., (1995). At the same time, the ovitraps were placed randomly at outdoor premises in a 
shaded area in order to measure the infestation of Aedes vectors. After consecutive days of exposure, the ovitraps were recollected and then were brought to the laboratory for egg count and species identification (Hasnan et al., 2017).

\section{Environmental Condition Assessment}

The purpose of this assessment is to evaluate the environmental condition including drainage facilities and solid waste management. The poorly built and improperly managed drainage system can contribute to the high mosquito infestation. For instance, the clogged drains with clear stagnant water are considered good artificial container to female mosquitoes that lay their eggs to complete the life cycle. Mosquito infestation can become worse when residents illegally dump the waste or garbage around the housing area. Meanwhile, the condition of the premises was observed if they are structurally well kept or poorly maintained that could contribute to mosquito infestation. Table 1 shows the descriptions of components and scores used to assess the environmental condition.
As for scoring of the environmental condition index (ECI), the house was classified into three classes. Score $1=$ well maintained house (structure in good condition, new paint, place is visibly clean and well maintained), Score 2 = reasonably well maintained (poor or simple structure, but well organised and clean) and Score 3 = poorly maintained (poor structure, peeling walls, broken or improvised items, little organisation or cleanliness). Yard classified as Score 1 = well maintained (organised, no apparent waste or scrap, grass is short, yard well maintained), Score 2 = reasonably well maintained (moderately well-kept or poor structure, but well organised and clean) and Score 3 = poorly maintained (disorganised, waste or scrap seen, unkempt grass, tires, bottles). The degree of shadow classified as Score $1=$ little or no shade (external area with less than $25 \%$ of 41 shade, no large tress or any other structure that works as a sunblind), Score $2=$ some shade (degree of shade in external area ranging from $25 \%$ to $50 \%$ ) and Score $3=$ plenty of shade (external area with over $50 \%$ of shade, large tress, a sunblind-like structure and layers

Table 1: The descriptions of components and scores used to measure the environment condition index (ECI) (Tun-Lin et al.,1995)

\begin{tabular}{|c|c|c|c|c|}
\hline Score & House Condition & Front/Yard Condition & Degree of Shade & Drainage Facilities \\
\hline 3 & $\begin{array}{l}\text { Poorly maintained } \\
\text { (poor structure, } \\
\text { peeling walls, } \\
\text { broken or } \\
\text { improvised items, } \\
\text { little organisation or } \\
\text { cleanliness) }\end{array}$ & $\begin{array}{l}\text { Poorly maintained } \\
\text { (disorganised, waste or } \\
\text { scrap, unkempt grass, } \\
\text { tires, bottles) }\end{array}$ & $\begin{array}{l}\text { Plenty of shade } \\
\text { (external area with over } \\
50 \% \text { of shade, large } \\
\text { tress, a sunblind-like } \\
\text { structure, and layers of } \\
\text { shrubs with a greenhouse } \\
\text { effect) }\end{array}$ & $\begin{array}{l}\text { Poorly maintained } \\
\text { (poor structure, } \\
\text { little organisation or } \\
\text { cleanliness) }\end{array}$ \\
\hline 2 & $\begin{array}{l}\text { Reasonably well } \\
\text { maintained (poor or } \\
\text { simple structure, but } \\
\text { well organised and } \\
\text { clean) }\end{array}$ & $\begin{array}{l}\text { Reasonably } \\
\text { well maintained } \\
\text { (moderately well-kept } \\
\text { or poor structure, but } \\
\text { well organised and } \\
\text { clean) }\end{array}$ & $\begin{array}{l}\text { Some shade (degree of } \\
\text { shade in external area } \\
\text { ranging from } 25 \text { to } 50 \% \text { ) }\end{array}$ & $\begin{array}{l}\text { Reasonably well } \\
\text { maintained (poor or } \\
\text { simple structure, but } \\
\text { well organised and } \\
\text { clean) }\end{array}$ \\
\hline 1 & $\begin{array}{l}\text { Well maintained } \\
\text { (structure in good } \\
\text { condition, new paint, } \\
\text { place is visibly clean } \\
\text { and well maintained) }\end{array}$ & $\begin{array}{l}\text { Well maintained } \\
\text { (organised, no apparent } \\
\text { waste or scrap, grass } \\
\text { is short, yard well } \\
\text { maintained) }\end{array}$ & $\begin{array}{l}\text { Little or no shade } \\
\text { (external area with less } \\
\text { than } 25 \% \text { of shade, no } \\
\text { large trees or any other } \\
\text { structure that works as a } \\
\text { sunblind) }\end{array}$ & $\begin{array}{l}\text { Well maintained } \\
\text { (structure in good } \\
\text { condition, well } \\
\text { organised and well } \\
\text { maintained) }\end{array}$ \\
\hline
\end{tabular}


of shrubs with a greenhouse effect. Whereas, the score of drainage facilities regarded as Score 1 $=$ well maintained (structure in good condition, well organised and well maintained), Score 2 $=$ reasonably well maintained (poor or simple structure, but well organised and clean) and Score 3 = poorly maintained (poor structure, little organisation or cleanliness). Finally, the environmental condition was classified based on the average score. The interpretations of the scores are: Good (Score $4 \&$ 5), Regular (Score $6 \& 7$ ), Bad (Score $8 \&$ 9) and the Worst (Score $10 \& 11)$.

\section{Infestation of Aedes Vector Using Ovitrap Surveillance}

A total of thirty ovitraps were placed randomly in each residential area and was predetermined to be placed outdoor. Wan Norafikah et al., (2011) mentioned that

all ovitraps should be placed in proximity to other potential breeding containers with minimum physical and environmental disturbance and then recovered after three to four days. Before that, the remaining water contained inside the ovitrap was not disposed, instead, it was kept and the ovitrap container was wrapped with plastic to prevent water from leaking and then brought to the insectarium. Next, the water in the ovitrap container was filtered in order to collect eggs that had fallen from the paddle.

\section{Data Analysis and Management}

(i) Environmental condition assessment: Premises was scored from lower to the highest. After scoring each parameter, the final score was evaluated to indicate the environmental condition of the residential area. (ii) Infestation of Aedes vectors: Positive ovitrap index (POI) was calculated and classified into four levels, namely level 1 (POI $<5 \%)$, level $2(5 \%<$ POI $<20 \%)$, level $3(20 \%<$ POI $<40 \%)$ and level 4 (POI $>40 \%$ ) to determine the infestation level. The trend analysis was used to determine the pattern of environmental condition and infestation level at selected residential areas. All statistical calculation was performed using Statistical Package for Social Science (SPSS).

\section{Results and Discussion}

A total of 318 households were inspected in both the front area $\left(\mathrm{F}_{\mathrm{A}}\right)$ and the yard area $\left(\mathrm{Y}_{\mathrm{A}}\right)$ for the presence of pre-mature and adult Aedes albopictus. The number and percent distribution of the positive houses according to the environmental condition assessment was ranked as shown in Table 2. The lowest score indicates a good condition and low risk for mosquito infestation at a residential area, while the highest score indicates the worst condition and favourable breeding environment for mosquitoes.

\section{Environmental condition assessment:} Generally, the majority of houses in the residential areas in Puncak Alam were classified as regular condition. Furthermore, the conditions of the front and the yard of houses were also evaluated where the yard condition recorded the highest score $\left(\mathrm{Y}_{\mathrm{A}}: 105\right)$ as compared to the front condition of the houses $\left(\mathrm{F}_{\mathrm{A}}\right.$ : 94). This finding indicates that the environmental condition in front of the houses is better than the yard area. This finding reflects the favourable breeding environment condition in residential housing areas (Figure 2). 


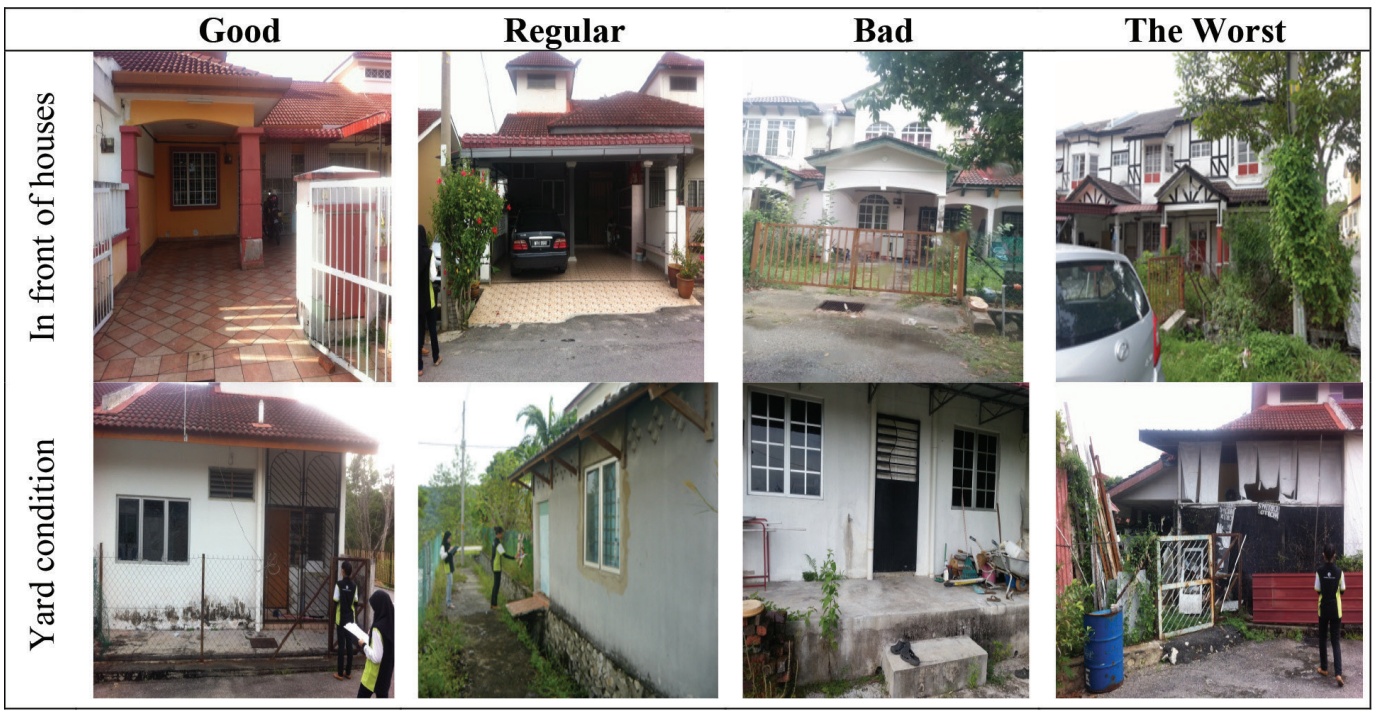

Figure 2: Environmental condition of housing in the residential area in the front and the yard conditions based on different scores, which reflect the favourable condition for Aedes vectors

Infestation profile of Aedes in residential areas: A total number of 270 ovitraps were deployed randomly which were placed in residential areas. During the survey, $87 \%$ - 90\% of ovitraps were recovered after four consecutive days. In general, all residential areas in both settings, either in the front of houses or the yard, the conditions had high infestation level and the POI percentage was recorded at more than $50 \%$ (Figure 3A). The results indicate that the residential area acts as the main area for distributing the dengue virus due to the availability of artificial breeding places, mainly caused by the surrounding conditions that are capable of storing water.

Trend analysis was conducted in searching the connection between the pattern of environmental condition and infestation of Aedes vectors in residential areas and this has led to a comparison of the environmental condition and infestation of Aedes vectors. This preliminary analysis has demonstrated that most of the high infestation of Aedes vector was observed in residential areas with bad environmental conditions. In fact, the possibility of detecting positive breeding of Aedes was higher in the premises with more shade (75\%) compared with very little shade (25\%). Furthermore, the ECI score in the front/yard conditions may affect the occurrence of the Aedes species eggs (Figure 3B).

From this study, some patterns of habitat preferences were observed. This result shows that the infestation of Aedes vectors in this study is related to human population and human activities due to some factors such as low relative shaded area at human settlement

(Gerusa et al., 2014; Dom et al., 2016). Polystyrene cups, tins and plastic bottles are widely used by our community nowadays. Improper disposal or littering of these materials may increase the number of containers made available for mosquitoes to breed. Source reduction or elimination is known as the most effective way to reduce the population of Aedes mosquitoes and the diseases they caused to = the human population. If the effort is done frequently it will lead to a permanent and effective control. Other than that, source reduction is also known as the most economical and easy method to be conducted within the affected areas of this disease-bearing insect. This can be done easily by turning upside down large earthenware to prevent Aedes female mosquitoes from breeding, 


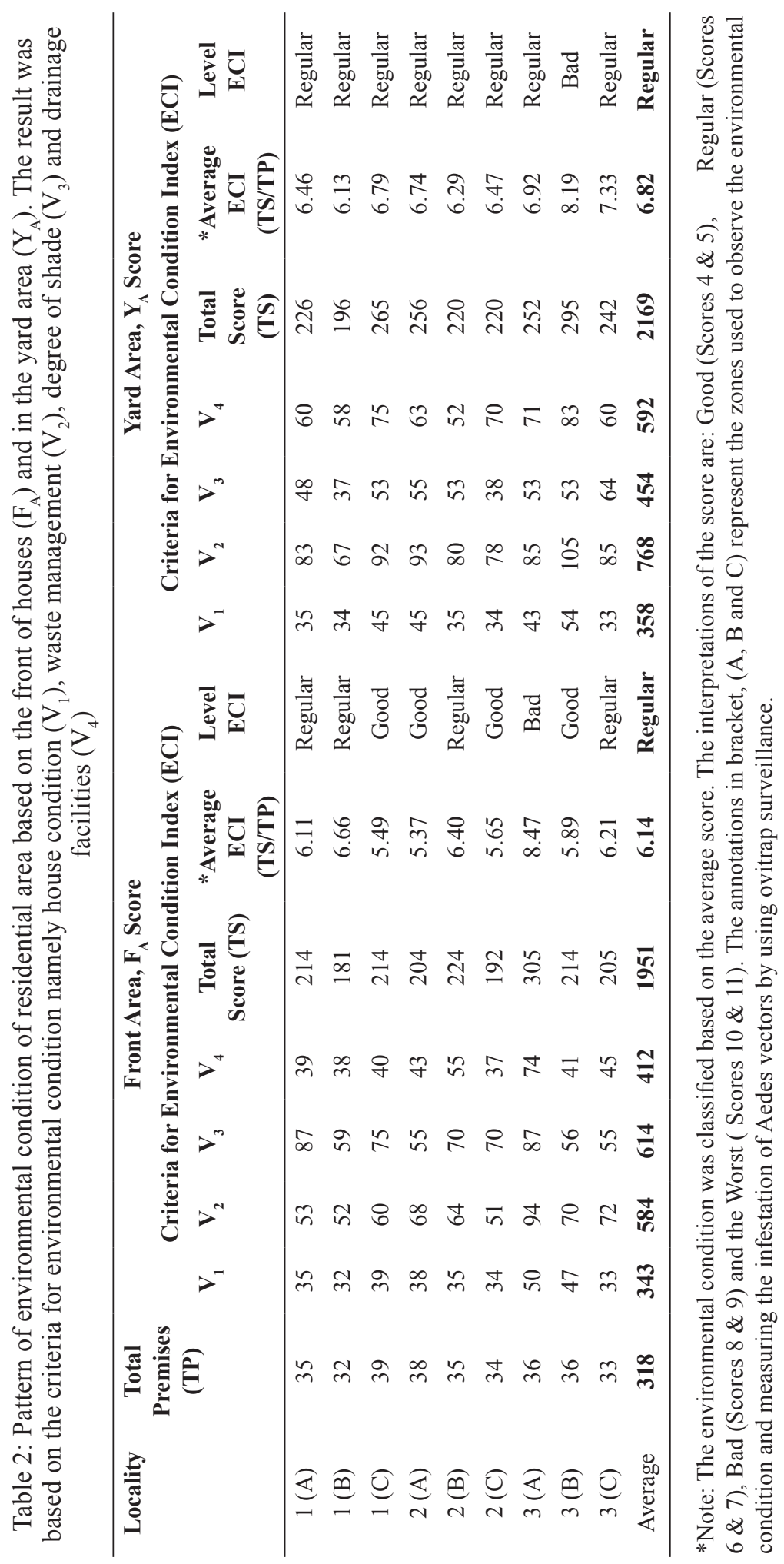




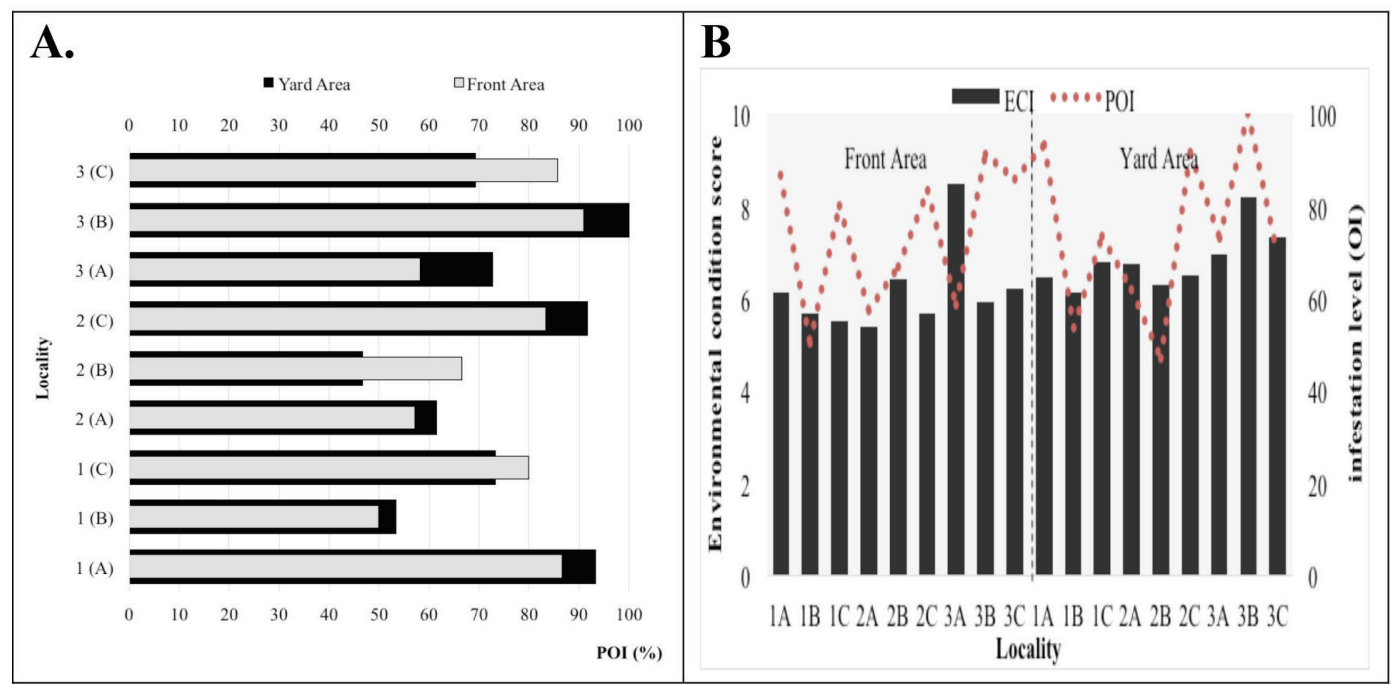

Figure 3: (A) Infestation profile of Aedes vectors in different settings in residential areas (B) Relationship of the environmental condition score with the infestation of Aedes vectors in residential areas.

discarding water retained from all old containers around the houses, as well as properly cleaning up all containers like flower vases that could retain stagnant water. Individuals should be tactful at all times and conduct self-inspection around their houses to see whether there are positive breeding sites under shaded trees or other hidden places that could retain water.

\section{Conclusion}

Overall this study found that environmental condition of houses may provide a favourable condition for the Aedes species. The conditions differ based on peoples' habits, such as in water management, water storage due to water scarcity, and works associated with water, like cement works. Thus, the use of ECI indicator can be used in improving the method for vector surveillance. An effective surveillance system is essential for planning, implementation, and monitoring of disease control programmes. Findings from this study help to conduct a rapid survey of Aedes mosquitoes in a place with a minimal number of manpower and in turn, with the help of ECI, delimitation is very possible in residential areas based on the sources of Aedes species breeding habitats. To employ ECI, more experimental studies may be required to make it more suitable

Community-based approach should go hand in hand with educational approach to ensure that the community is exposed to the knowledge of vector control and what the diseases are that vectors would likely spread. Several parties like JKKK (Jawatankuasa Kemajuan Kampung) and RT (Rukun Tetangga) should play their roles in taking care of safety, health and welfare of the community in their areas. This could be done through "gotong-royong" by cleaning the areas and compounds that are prone to be mosquito breeding sites. Also, they can together clean up clogged drains and unused wells to prevent the breeding. Communities that understand the need to make behavioural changes are the ones that are most effective in controlling diseases like dengue.

\section{Acknowledgements}

The authors would like to sincerely thank the Ministry of Health, Malaysia for providing ground data on dengue surveillance for this research work. University of Technology MARA and the Ministry of Higher Education (MOHE) Malaysia are also duly acknowledged. 


\section{References}

Aziz, A., Abdullah, R., Ibrahim, H. (2011). A model of knowledge mapping in visualizing the hotspot of dengue. In Open Systems (ICOS), 2011 IEEE Conference on (pp. 444-449). IEEE.

Dom, N., Faiz Madzlan, M., Nadira Yusoff, S. N., Hassan Ahmad, A., Ismail, R., Nazrina Camalxaman, S. (2016). Profile distribution of juvenile Aedes species in an urban area of Malaysia. Transactions of the Royal Society of Tropical Medicine and Hygiene, 110(4), 237-245.

Gerusa G., Reinaldo S. S., Nildimar A. H., \& Antonio Guilherme P. (2014).

Condition of the household and peridomicile and severe dengue: a case-control study in Brazil. Infection Ecology \& Epidemiology, 4, 22110.

Hasnan, S. N. A., Che-Dom, N., Abd-Latif, Z., \& Madzlan, F. (2017). Surveillance of Aedes mosquitoes in different residential types in central zone of Shah Alam, Selangor. Asian Pacific Journal of Tropical Disease, 7, 332340.

Hayden, M. H., Uejio, C. K., Walker, K., Ramberg, F., Moreno, R., Rosales, C., \& Janes, C. R. (2010). Microclimate and human factors in the divergent ecology of Aedes aegypti along the Arizona, US/ Sonora, MX border. EcoHealth, 7(1), 64-77

Idris, F. H., Idris, A., Usman, S. N. (2013). Surendran, R. Ramasamy. Detection of Aedes albopictus pre-imaginal stages in brackish water habitats in Brunei Darussalam. Journal Vector Ecology, 38(1), 197-199.

Leticia A., Nogueira, Leticia T., Gushi, Joao E., \& Miranda. (2005). Short report: application of an alternative Aedes species (diptera: culicidae) surveillance method in Botucatu city, Sao Paulo, Brazil. The American Journal of Tropical Medicine and Hygiene, 309-311.
Ligia L. N. S. G., Ana P. L., Julio C. V., Marylene B. A., V., G. V. (2013). Study of the distribution and abundance of the eggs of Aedes aegypti and Aedes albopictus according to the habitat and meteorolical variables, municipality of Sao Sebastiao, Sao Paulo State, Brazil. Parasites \& Vectors, 6, 321

Nazni, W. A., Lee, H. L., Wan Rozita, W. M., Lian, A. C., Chen, C. D., Azahari, A. H. Sadiyah, I. (2009). Oviposition behaviour of Aedes albopictus in temephos and Bacillus thuringiensis israelensis-treated ovitraps. Dengue Bulletin, 33, 209-216.

Pablo Manrique-Saide, Clive R. Davies, Paul G. Coleman and Azael Che-Mendoza. (2013). The risk of Aedes aegypti breesing and premises condition in South Mexico. Journal of the American Mosquito Control Association,337-345.

Paily K. P. Paily, K. Chandhiran, P. Vanamail, N. P. Kumar, P. Jambulingam. (2013). Efficacy of a mermithid nematode Romanomermis iyengari (Welch) (Nematoda: Mermithidae) in controlling tree hole-breeding mosquito Aedes albopictus (Skuse) (Diptera: Culicidae) in a rubber plantation area of Kerala. India Parasitology Research, 112(3), 1299-1304

Parasuraman B., \& Radhakrishnan E. (2012a). Study on the correlation of premises condition index and the presence of larvae of Aedes species mosquitoes in human dwellings of the Cuddalore district of Tamil Nadu, India. Osong Public Health and Research Perspectives, 3(1), 3-7. 7

Parasuraman B., \& Radhakrishnan E. (2012b). Study on the correlation of premises condition index and the presence of larvae of Aedes species mosquitoes in human dwellings of the Cuddalore district of Tamil Nadu, India. Osong Public Health and Research Perspectives, 3(1), 3-7. 7.

Ramasamy, R., Ramasamy, S. N., Surendran, P. J., Jude, S. Dharshini, M., \& Vinobaba. (2011). Larval development of Aedes 
aegypti and Aedes albopictus in peri-urban brackish water and its implications for transmission of arboviral diseases. PLoS Neglected Tropical Diseases, 5(11), e1369

Roberto C. P., Reginaldo R., and Farael M. F. (2013). The use of the premise condition index (PCI) to provide guidelines for Aedes aegypti surveys. Journal of Vector Ecology, 190-191.

Rozilawati, H., Zairi, J., and Adanan, C.R. (2007). Seasonal Abundance of Aedes albopictus in Selected Urban and Suburban Areas in Penang, Malaysia. Tropical Biomedicine, 24(1), 83-94.

Saleeza S. N. R., Norma R. Y., and Sofian M. (2011). Mosquitoes Larval Breeding Habitat in Urban and Suburban Areas, Peninsular Malaysia. World Academy of Science, Engineering and Technology, International Journal of Biological, Biomolecular, Agricultural, Food and Biotechnological Engineering, 5(10), 599-603.

Sarfraz, M. S. Sarfraz, N. Tripathi, T. Tipdecho, T. Thongbu, P. Kerdthong, M. Souris. (2012). Analyzing the spatio-temporal relationship between dengue vector larval density and land-use using factor analysis and spatial ring mapping. BMC Public Health, 12(1), 853.

Sumodan, P. K. \& Sumodan (2013). Potential of rubber plantations as breeding source for Aedes albopictus in Kerala, India. Dengue Bull, 27, 197-198.

Tun-Lin, W., Kay, B. H., Barnes, A. (1995). The premise condition index: a tool for streamlining survey of Aedes aegypti. The American Journal of Tropical Medicine and Hygiene, 591-594.

Vezzani, D., Vezzani, A., Rubio, S. M., Velazquez, N., Schweigmann, T., Wiegand. (2005). Detailed assessment of microhabitat suitability for Aedes aegypti (Diptera: Culicidae) in Buenos Aires, Argentina. Acta Trop, 95(2), pp. 123-131.

Wan-Norafikah O., Chen C.D., Soh H.N., Lee H. L., Nazni W. A., Sofian- Azirun M. (2009). Surveillance of Aedes mosquitoes in a university campus in Kuala Lumpur. Malaysia. Tropical biomedicine, 26(2), 206-215 